\title{
Deleuze e Guattari e a Psicologia Cognitiva, IA e IHC: investigando possíveis conexões e diferenças.
}

\author{
Deleuze and Guattari's Works and Cognitive Psychology, AI, and HCI: Investigating the \\ Possible Differences and Connections
}

\author{
Ronald E. Day \\ $\mathrm{PhD}$, State University of New York \\ Professor Associado da Indiana University \\ E-mail: day@indiana.edu
}

\section{Resumo}

A relação da obra de Deleuze e Guattari e a ciência cognitiva, a Inteligência Artificial (IA), e a Interação Humano-Computador (IHC) é complicada: em alguns aspectos, tais como os apresentados neste artigo, os compromissos ontológicos do cognitivismo clássico e da IA tradicional não poderiam ser mais distantes daqueles de Deleuze e Guattari em relação a uma filosofia expressionista. Por outro lado, os compromissos ontológicos do conceito de cérebro dos autores (Deleuze e Guattari, 1994), entendido como um órgão moldado por estímulos externos são de alguma maneira próximos àqueles da ciência cognitiva e mais contemporaneamente, da ciência do cérebro. O objetivo desse artigo é estabelecer este diálogo entre a obra de Deleuze e Guattari e a ciência cognitiva e a IA através de três conceitos deleuzianos relacionados ao tema: a relação do desejo com os objetos (via objetos parciais), o conceito de "mapas" relacionado à representação, e o conceito de "máquinas" e agenciamentos "maquínicos".

Palavras-chave: Deleuze, Guattari, ciência cognitiva, inteligência artificial, interação homem-computador, máquinas.

\begin{abstract}
The relation of Deleuze and Guattari's works to cognitive science, Artificial Intelligence (AI), and HumanComputer Interaction (HCI) is complicated: in some aspects, such as the ones touched upon in this article, the ontological commitments of classic cognitivism and traditional AI couldn't be more distant from Deleuze and Guattari's commitments to an expressionist philosophy. On the other hand, the ontological commitments of Deleuze and Guattari's concept of the brain (Deleuze and Guattari, 1994), understood as a physiological organ that is shaped by external stimuli, is in some ways very close to those of cognitive science and more contemporarily, "brain science." The purpose of this article is to enter into this dialogue between Deleuze and Guattari's works and cognitive science and AI through three, related, Deleuzian concepts: desire's relationship to objects (via part-objects), their concept of "maps" in relation to representation, and their concept of "machines" and "machinic" assemblages.
\end{abstract}

Keywords: Deleuze, Guattari, cognitive science, artificial intelligence, human-computer-interaction, machines

InCID: R. Ci. Inf. e Doc., Ribeirão Preto, v. 1, n. 2, p. 03-20, jul./dez. 2010. 


\section{Introdução: A obra de Deleuze e Guattari e Ciência Cognitiva, Inteligência artificial, e Interação Humano Computador.}

A inteligência artificial tradicional está baseada na premissa de que o agente computacional é um modelo para a cognição humana. O tipo de agente computacional é aquele do processamento da máquina digital, o qual estabelece o hardware e o software variável. Este modelo, que vê a cognição humana em analogia ou modelada pelos computadores digitais, tem sido modificada em diferentes aspectos através dos anos, modelando de diferentes maneiras esse processamento (por exemplo: processamento lógico e abordagens conexionistas) para diferentes maneiras de visualizar a relação do "software" e do "hardware" (exemplo: neuropsicologia que tenta encontrar o processamento cognitivo em funções cerebrais) (veja Ekbia (2008) para uma boa revisão crítica de abordagens em Inteligência Artificial). Enquanto alguns (WATSON, 1998) tem sido capazes de reconciliar o trabalho de Deleuze e Guattari com certas abordagens da ciência cognitiva, e tem havido uma tendência popular para ver o trabalho de Deleuze e Guattari propondo o apagamento das diferenças entre agentes humanos e maquínicos (isto é, na figura do cyborg), argumentarei neste artigo, que há problemas em ambas as leituras. Embora nenhuma das leituras sejam totalmente incorretas, os trabalhos de Deleuze e Guattari portam nuances que permitem propor tanto críticas quanto acréscimos aos debates em inteligência artificial e interação homem-computador. Neste artigo estarei enfatizando não apenas a conjugação dos agenciamentos homem-computador, mas também as limitações dessas conjugações de acordo com diferentes poderes de agentes orgânicos e inorgânicos.

Tradicionalmente no pós-guerra, a ciência cognitiva e a Inteligência Artificial tem usado um "modelo individual" para mentes e uma epistemologia do processamento da informação para o pensamento. Entretanto, considerar a mente como uma máquina computacional individual - em particular, como uma máquina de processamento da informação para "representações do conhecimento" (entendido como análogo à estrutura de dados) - é problemático por uma série de razões que têm sido bem discutidas por vários autores, recentemente. Assim, a virada da ciência cognitiva, de um "modelo individual" da mente para um modelo de cognição situada, encontra ressonância também na Inteligência Artificial: nomeadamente, o abandono da IA tradicional e uma virada para uma IA implicada (embedded) e à Interação Homem-computador (IHC) 
Deleuze e Guattari obviamente rejeitam as compreensões metafísicas da cognição humana baseadas em modelos de pensamento "individualistas" ou "individuais". A noção desses autores de organismo é sempre aquela que os vê como "singularidades" relacionadas a múltiplas evoluções histórico-sociais e afetos. Também, a epistemologia desses autores está baseada em uma teoria dos afetos, e não em uma teoria do processamento simbólico. Portanto, como críticos da tradição clássica, a sua teoria é também critica da tradição metafísica, como encontrada na psicologia tradicional e na IA. Restam as perguntas: como esta teorização ecoa nas noções implícitas da inteligência artificial? Como se relaciona aos estudos da interação humano-computador? Para responder a essas questões devemos considerar os conceitos de afeto e expressão considerando: quais são os limites e as possibilidades teóricas e práticas do pensamento de Deleuze e Guattari nos conceitos de "agenciamentos maquínicos" para pensar a IA e a IHC?

A proposta deste artigo é estabelecer um diálogo entre o pensamento de Deleuze e Guattari, a ciência cognitiva e a IA através de três conceitos deleuzianos relacionados ao tema: a relação do desejo com os objetos (via objetos parciais), o conceito de "mapas" relacionado à representação, e o conceito de "máquinas" e agenciamentos "maquínicos". A proposta aqui não é fazer uma exploração extensiva a respeito da relação Deleuze-GuattariCiência Cognitiva/IA, mas propor uma apresentação inicial de três áreas importantes na obra de Deleuze e Guattari, que podem contribuir para o desenvolvimento de uma nova teoria psicológica híbrida.

\section{Desejo e objetos parciais}

Primeiro, gostaria de sugerir, que o primeiro passo para entender entidades como ferramentas do desejo, pode ser encontrado na discussão de objetos parciais descritos no AntiÉdipo (Deleuze e Guattari, 1983) e em Mil Platôs (Deleuze e Guattari, 1987). Esses trabalhos propõem uma conceituação de agenciamento e formação psicológica individual e social que é explicitamente desenvolvimentista e política:

as pulsões e objetos parciais não são nem estágios sobre o eixo genético, nem posições numa estrutura profunda, são opções políticas para problemas, entradas e saídas, impasses que a criança vive politicamente, quer dizer, com toda a força de seu desejo. (DELEUZE; GUATTARI, 1987) 
O conceito de desejo de Deleuze e Guattari é, naturalmente, emprestado da psicanálise, particularmente, da tradução francesa (désir) do termo freudiano wunsch (wishdesejo). O termo, entretanto, também parte da descrição hegeliana da dialética; o desejo é a força entre o sujeito e o outro através da qual o sujeito realiza a si mesmo, através, mas não como, o outro (a influência de Hegel sobre Lacan, via Kojèv, não pode ser esquecida). Enquanto o termo freudiano em alemão tem mais o sentido de fantasia do próprio sujeito, em francês, o termo tem mais o sentido de uma força que vincula o sujeito ao outro, ou ao objeto. Então o desejo é o meio através do qual, não somente a ação ocorre como pretendida, mas é o meio através do qual a intenção e a subjetividade são criadas. Em resumo, para Deleuze e Guattari não há intenção sem desejo e não há desejo sem objeto. Enquanto o wunsch de Freud carrega mais o sentido de uma intenção "consciente" ou "inconsciente" - de uma mimese projetiva - o termo em francês traz o entendimento de um sujeito no caminho de uma relação - uma relação social. Esta "interpretação francesa" do trabalho de Freud não pode ser subestimada, ao tentar entender o papel da psicanálise na "teoria francesa" e a relação crítica da tradição francesa psicanalítica em relação à psicanálise ortodoxa tradicional.

O entendimento do sujeito em termos de desejo e de objeto parcial psicanalítico traz vários efeitos para o entendimento da subjetividade. Antes de tudo significa que o sujeito é investido com seu ser através do "objeto" e que este investimento é constitutivo para o sujeito. Como é bem conhecido, para Lacan, este investimento segue a lógica do especular ou imaginativo (no "estágio do espelho" do desenvolvimento) e, então, mais tarde no desenvolvimento do sujeito, a lógica do simbólico (entendida em termos de linguagem). O real é a lembrança deste investimento, que contribui e excede o simbólico e mesmo o imaginário de várias maneiras. Daí vem a comédia lacaniana ou a tragédia da consciência de si mesmo com um self "dividido". Em contraste com Lacan, para D e G o "outro" (não importa qual a sua composição ontológica) é “entradas e saídas” (DELEUZE; GUATTARI, 1987, p. 13) através das quais o sujeito passa nos seus “devires”. Além disto, as possibilidades e potencialidades para estes investimentos e "transformações do self' são produtos de campos sociais de materiais semióticos e físicos. Através do campo social e de seus objetos, o sujeito inventa a si mesmo e seus próprios significados, para si e para os outros, como realizações (através de possibilidades de expressão) e como atualizações (através de potencialidades de expressão). 
Como é possível "passar através" do outro como uma "entrada e saída" se tomarmos o outro como ser humano, outro tipo de ser vivente, ou mesmo um objeto inanimado (incluindo agentes tecnológicos)?

Classicamente, na psicanálise, a mimese epitomizada no "estágio do espelho" de Lacan é o meio pelo qual "nos tornamos" através de um outro. Entretanto, em Lacan, a maturidade significa um envolvimento maior no "simbólico" mais do que meramente nas relações especulares. Para Lacan, a identidade é obtida (ou, em última análise, reconhecida como sempre em errância) pela passagem do sujeito através de campos simbólicos que não apenas marcam a relação do objeto com o self, mas que, em última análise, marca a alteridade do "outro" ou "outridade" para o self (incluindo a composição do próprio self na alteridade da linguagem). Nos escritos de Lacan a alteridade do campo social através do qual o sujeito precisa passar é o que constrói a identidade absoluta, seja com o outro, seja consigo mesmo, mesmo que impossivelmente adiada.

Mais do que deixar a questão do self na esteira de um mau reconhecimento fútil e vão, Deleuze e Guatarri vêm o engajamento com o outro nem como trágico ou cômico, nem como uma questão de mímesis ou não. De fato, a dialética é substituída pelo expressionismo como uma epistemologia e política preferidas. Tendo já rejeitado o Eu cartesiano como uma tradição metafísica errônea (extensiva através de Hegel) que valoriza o ser sobre o devir, Deleuze e Guattari entendem o ser como sendo sempre provisório e derivado de devires oriundos de afetos e expressões. Para estes autores, em outras palavras, o devir é a natureza da vida, e é sempre um processo de tornar-se através dos outros. A maturidade para Deleuze e Guattari não é uma questão de progredir do devir para o ser, mas de ter uma chance cada vez maior de determinar a natureza dos devires - isto é, em ter maiores habilidades de perguntar para que serve um corpo? Em termos de aberturas e fechamentos do sujeito aos afetos e, então, aos seus possíveis devires em comum com outros. Se as crianças e os adolescentes são valorizados na obra de Deleuze e Guattari por serem mais "moleculares" do que "molares", o ponto de valorização é argumentar que a "molaridade" que advém com a idade é relativamente mais possível e menos potente (portanto, mais restritiva e "intencional") que a "molecularidade" da infância e da juventude - devires, entretanto, permanecem a "vitalidade" da vida para ambos, as crianças e os adultos. Enquanto que as aberturas das crianças para todos os tipos de associação é uma coisa para ser imaginada e valorizada através de devires transversais e nas palavras de Nietzsche, a "reavaliação dos valores" (daí a importância da figura da criança na obra de Nietzsche), os adultos têm a chance de escolher InCID: R. Ci. Inf. e Doc., Ribeirão Preto, v. 1, n. 2, p. 03-20, jul./dez. 2010. 
melhor seus devires, mas, menos potencialidade em termos de campos sociais transversais (através dos quais a experiência pode ser obtida e então, escolhida). Na obra de Deleuze e Guattari não podemos nunca escapar do social e isto faz a transversalidade nos adultos ainda mais interessante, justamente por ser mais rara.

Assim, a valorização das crianças e adolescentes em Deleuze e Guattari, na natureza manifesta de seus devires e na natureza "transversal" de tais devires, deve ser vista como uma posição crítica frente à vida, levada dentro de formas psicológicas e estruturas sociais, sistematicamente repetidas. (DELEUZE, 1977). O que está em questão não é a celebração da imaturidade ou da doença mental, mas a natureza destes devires em comparação com estruturas dominantes da "maturidade" (como valorizado pela psicanálise, na norma do Édipo e pelo capitalismo na sua valorização da acumulação) e em termos do que Deleuze chamou de "sociedade de controle" (DELEUZE, 1990). Estas críticas têm um longo precedente na crítica deleuziana à "representação", na tradição metafísica filosófica (por exemplo, em Diferença e Repetição (DELEUZE, 1994), e no trabalho teórico de Guattari a respeito da psicanálise radical. A concepção de Deleuze e Guattari da pessoa como "molecular" e formatada pela intensidade e velocidade dos afetos guarda, ainda, possibilidades inexploradas para a psicologia clínica e do desenvolvimento.

As teorias cognitivistas do desenvolvimento tendem a localizá-lo em mudanças na estrutura do cérebro. A concepção psicanalítica do desejo e a ênfase de Deleuze e Guattari no desenvolvimento como uma função de um corpo desterritorializado, portanto, vê o desenvolvimento em termos de afetos que resultam em atração ou repulsão e em formação correspondente de aberturas e fechamentos. De acordo com a ética espinosista das paixões alegres ou tristes, as conjunções e sínteses, bem como as disjunções, seguem o "desejo" subjetivo como "linhas de fuga". Assim, a cognição, na estrutura de Deleuze e Guattari deve ser vista como uma variação de escolhas dentro do vivido. Não existe uma cognição fora do vivido na obra de Deleuze e Guattari. Os "agenciamentos maquínicos" particularmente descritos por Guattari, são, antes de tudo, funções situadas. Linhas de fuga ou "devires" são produtos de afetos situados. O conceito de desejo deve ser entendido em termos de histórias de afetos situados. O sujeito é produto destes afetos dentro do contexto de sua própria singularidade.

InCID: R. Ci. Inf. e Doc., Ribeirão Preto, v. 1, n. 2, p. 03-20, jul./dez. 2010. 


\section{Mapas}

A crítica de Deleuze da representação, em termos de devires transversais, na psicologia do desenvolvimento e sociedade, é importante, no escopo deste artigo, porque envolve representações e "mapas" - dois importantes termos para a psicologia cognitiva, IA e IHC. A crítica de Deleuze da representação se faz a respeito da reprodução de formas conceituais que impossibilitam o aparecimento de novas formas. A "representação" é apresentada como uma tendência "territorializante" com relação à formação conceitual. Vistas psicologicamente, as críticas de Deleuze e Guattari são dirigidas às normas psicológicas e éticas, que limitam os movimentos transversais, pelos planos semióticos e pelos corpos físicos que as crianças e adolescentes são capazes, particularmente aquelas normas que agem no controle, não somente da produção de novas linhas de fugas ou devires, mas que também agem para multiplicar sua própria produção (neste sentido a crítica de Deleuze à representação é próxima a de Althusser e de muitos outros - crítica da ideologia; isto é, da representação, entendida como precedente à reprodução de formas estabelecidas e de eventos (isto é, devires) para territorializar, direcionar e constranger novas formas e eventos). Deleuze, usando o termo foucaultiano "sociedade de controle", discute esta sociedade em termos de uma micropolítica de expressões limitadas e uma educação e sistemas sociais baseados em experiências, expectativas e afetos padronizados (DELEUZE, 1990). Não é por acaso, então, que Deleuze reconhece a formação e a continuidade da sociedade de controle em instituições como "educação continuada" e "educação profissional" que transformam todo processo da vida humana em uma educação e reeducação dentro de normas sociais de controle e de autocontrole. Assim, a "sociedade de controle" de Deleuze trata da sociedade disciplinar do Foucault, feita ainda mais imanente, pelo treinamento que enfatiza regras linguísticas e outras normas "infra estruturais" para expressão individual e coletiva, particularmente direcionadas à manutenção da reprodução destas normas e do tratamento de outros valores como marginais, do ponto de vista clínico e social (e ameaçador do ponto de vista pessoal e social).

O significado do termo "mapas mentais" na ciência da informação refere-se a modelos prescritivos de ação e pensamento e é algo falado na ciência cognitiva como sinônimo de estruturas, esquemas ou roteiros. Na teoria de Deleuze e Guattari a noção de "mapa" refere aos traços trajetória percorrida pelos agentes, em seus devires transversais. Ausentes na teoria de Deleuze e Guattari estão as noções de representações como re-apresentações, de imagens 
ou eventos na mente ou no cérebro (embora seus escritos sobre o cérebro permitam um certo tipo de inscrição materialista - a modificação do cérebro pelos afetos). As representações como um processo lógico ou retórico são entendidas em termos de discurso, "palavra de ordem” (DELEUZE; GUATTARI, 1987) e como certos agenciamentos conceituais. "Mapas" são compreendidos como movimentos através de eventos, como registrados pelo corpo, inclusive pelo cérebro. Não são descrições ou representações imagéticas, nem mesmo prescrições, mas registros de eventos, em termos de afetos que nos deixam abertos ou fechados para novas afecções e devires, e, para novos traçados ou mapas. Inscrições mentais de afetos não são "re-apresentações" de experiências porque estas não são compreendidas como eventos empíricos sui generis reproduzidos na mente (entendida como análise epistêmica do cérebro).

O trabalho de Deleuze e Guattari enfatiza o conceito de evento constituído por temporalidade radical e emergências singulares. Qualquer ciência cognitiva baseada em normas e qualquer concepção de inteligência artificial são desafiadas por esta ênfase.

Na linguagem de Deleuze, se os homens são caracterizados como potencialidades a serem atualizadas, então, as máquinas computacionais são possibilidades a serem realizadas. Estas duas formas diferentes de mapa e mapeamento, podem e devem ser levadas em consideração, tanto do ponto de vista histórico quanto conceitual. Tradicionalmente, na cibernética e na linhagem histórica da sociedade de controle ou da "sociedade da informação", a tendência tem sido funcionalizar as atividades humanas dentro de padrões sistêmicos, projetados e previsíveis (por exemplo, o agente humano de Norbert Wiener como posicionado na servomecanismos dos armamentos ou na compreensão de Wiener da linguística, como normativa, na linguística "democrática" da "clara" comunicação. Enquanto a crítica disto em ambas teorias conservadoras (por exemplo Heidegger) e da arte de esquerda (por exemplo avant-gard moderna) privilegiam a arte, como horizonte crítico e como limite possível, para o controle cibernético da sociedade e suas funções e instituições, a crítica de Deleuze e Guattari se centra, em parte, na psicologia do desenvolvimento humano e na resistência às normativas e na valorização do "devir". Além disto, as figuras em Deleuze e Guattari que sinalizam a resistência e os devires são aquelas das crianças e dos esquizofrênicos. A seguir, nos concentraremos na concepção de esquizofrenia de Deleuze e Guattari e na interface humano-computador. 


\section{Agenciamentos esquizofrênicos e maquínicos}

A pesquisadora de Inteligência Artificial e Interação Humano-Computador Phoebe Sengers faz uma análise bastante didática e interessante da IA usando a metáfora da esquizofrenia (SENGERS, 2002). Evidentemente, uma proposição como esta soaria herética no âmbito da IA, uma vez que a IA pretende incorporar e modelar um padrão cognitivo e normativo do comportamento. A análise feita por Sengers não apenas critica a IA tradicional apontando a necessidade de ir além dela em direção a uma perspectiva mais contextualizada da IHC, como também oferece um horizonte para examinarmos as proposições de Deleuze e Guattari sobre a esquizofrenia e o esquizo em relação aos agenciamentos homem-computador.

No artigo de 2002 "Esquizofrenia e narrativa nos agentes computacionais", Sengers argumenta que os agentes de inteligência artificial têm apresentado até agora características semelhantes às dos pacientes esquizofrênicos. Além disto, os sistemas de IA não disporiam de

\footnotetext{
[...] uma consciência primitiva, uma linha de ação consistente ao longo do tempo, algo que poderíamos designar, à falta de melhor metáfora, como 'alma.Meu argumento aqui é de que o 'suco' de que estamos sentido falta é a narrativa. As técnicas do tipo 'dividir-e-conquistar' que vêm sendo utilizadas para projetar os agentes computacionais resultam em comportamentos fragmentados, despersonalizados, que imitam a fragmentação e a despersonalização da esquizofrenia tal como vista na psiquiatria. Os movimentos da Antipsiquiatria e da Psicologia da Narrativa propõem que o problema fundamental tanto para pacientes esquizofrênicos quanto para os agentes artificiais é que os observadores externos têm dificuldades para entender sua narrativa. (SENGERS, 2002, p. 427)
}

Aqui caberia um aparte para reforçar que a crítica de Sengers não se dirige exclusivamente a IA como um modelo que não dá conta de entender o comportamento humano padrão; em outro trecho do artigo, ela vai também criticar a psiquiatria institucional por falhar ao não conseguir tratar os esquizofrênicos como pessoas. Para Sengers, a própria psiquiatria poderia ser caracterizada como um transtorno social ou institucional, em função de sua característica de fixação em uma epistemologia de processamento de informação questão também assinalada e analisada historicamente por Jackie Orr em seu trabalho sobre síndrome do pânico (ORR, 2006).

Globalmente, a ênfase de Sengers no fato de as máquinas de IA carecerem de "uma coerência de ação ao longo do tempo" nos remetem à proposição de Kant de uma unidade transcendental da percepção, tal como defendida em sua "Crítica da Razão Pura". No âmbito dos estudos psicológicos mais contemporâneos, podemos lembrar o conceito de Rom Harré

InCID: R. Ci. Inf. e Doc., Ribeirão Preto, v. 1, n. 2, p. 03-20, jul./dez. 2010. 
de self como continuidade hipotética de habilidades potenciais desenvolvidas ao longo do tempo através da ação (HARRÉ, 1998). Na obra de Deleuze e Guattari, o conceito de desejo refere-se a uma subjetividade contínua ao longo do tempo, e noções como "devir" , "linha de fuga", "mapas" e "diagramas" todas fazem parte deste conceito. Selves e pessoas são entendidas como unidades na perspectiva de um continuum entre passado, presente e futuro. A narrativa é a forma literária que corresponde a essas unidades. A extensão do conceito de narrativa aos relatos causais das ações e acontecimentos do dia a dia é uma aplicação comum deste termo.

O argumento de Sengers é de que esta linha de continuidade é o que falta nas máquinas de inteligência artificial. Citando "O eu dividido: estudo existencial da sanidade e da loucura" de Ronald Laing, a autora ressalta que a "salada de palavras" do esquizofrênico é um indicativo de sua característica "falta de unidade e fragmentação naquilo que poderia ser alternativamente chamado de "agenciamentos" parciais, sistemas complexos e parciais, ou 'objetos internos"” (SENGERS, 2002, p. 428). Enquanto Deleuze e Guattari valorizam esses objetos parciais através dos quais passa o desejo, o problema da esquizofrenia enquanto doença é o fato de seus "agenciamentos maquínicos" não serem coerentes em termos de duração; assim, nas palavras de um esquizofrênico citado por Sengers, a pessoa sente que "é uma máquina”.

Inevitavelmente, vem a pergunta: por que a noção de Deleuze e Guattari, de "máquinas" como agenciamentos de partes, consegue ser tão padronizada a ponto de o conceito de esquizofrenia ser também estendido para os comportamentos funcionais (ditos normais), ao passo que a concepção de Sengers dos esquizofrênicos como máquinas vem marcada pelo desvio e pelo isolamento social? Uma maneira de reformular a questão seria: qual a diferença entre os agenciamentos maquínicos com que trabalham Sengers e outros pesquisadores de IA e os agenciamentos humanos? A resposta a esta questão poderia ajudar a estabelecer a diferença entre os esquizofrênicos literais de Sengers e Laing e aquelas figuras esquizo que são valorizadas por Deleuze e Guattari. Enquanto a concepção da ação esquizo em Deleuze e Guattari não está dissociada do comportamento esquizofrênico no sentido estrito, "esquizofrenia" e outros termos associados são apropriados e estendidos em seu discurso para uma análise crítica social e política, uma crítica dirigida não apenas à psicanálise ortodoxa, mas também ao capitalismo e outros agenciamentos sócio-técnicos. 
Uma resposta possível ao que diferenciaria os agenciamentos humanos dos tecnológicos remete, em parte, às noções de desejo e afeto que informam as análises de Deleuze e Guattari em "O Anti-Édipo" e, de modo mais geral, refere-se também à natureza temporal do "devir" discutida em seus outros trabalhos. O interesse que Deleuze e Guattari encontram no esquizofrênico reside nos movimentos transversais entre diferentes regimes e sua abertura e fechamento com relação à capacidade de estabelecer de outra forma relações afetivas com os demais seres e objetos, relativamente desembaraçados de normas sociais ou de experiências e categorizações prévias, e relativamente mais propensos a serem capturados em blocos de sensações ou afetos (neste sentido, o esquizofrênico que emerge não é muito diferente das crianças). Desta maneira, a transversal "transvaloração dos valores" (Nietzsche) feita pelo esquizofrênico é valorizada contra, sobretudo, o estatuto do Édipo na estrutura da psicanálise ortodoxa. É preciso assinalar que esta valorização tem em Deleuze e Guattari uma dimensão ontológica; trata-se, mais precisamente, da valorização de uma temporalidade radical através da qual a repetição se torna transformação por via do movimento entre diferenças, o que não pode ser recuperado no contexto do "estado" edipiano (tanto em termos de uma normatividade familiar quanto uma normatividade política). Esses diferentes lócus de atualização conferem uma dimensão espacial à "diferença", aproximando o desdobramento temporal das múltiplas potencialidades virtuais à singularidade dos acontecimentos, processo através do qual os sujeitos se transformam e são alterados por outros seres ou objetos.

No entanto, enquanto os objetos e outros seres podem possíveis canais do desejo, para os esquizofrênicos os objetos nunca atuam consistentemente como "portas de entrada e saída" para o real. É esta falta de consistência e a inabilidade de passar do imaginário à realidade que caracteriza as ações e expressões do esquizofrênico e que pontua as ações e expressões das máquinas artificiais analisadas por Sengers. Para os esquizofrênicos, os objetos parciais permanecem atados ao imaginário, seja qual for sua eficácia simbólica, e assim, ao invés de serem "transicionais" (Winnicott) ou "portas de entrada e saída", acabam sendo objetos do imaginário, proporcionando ao sujeito experiências de mimetismo alucinatório e desorientação real. Se o esquizofrênico é incapaz de construir um "mapa" (DELEUZE; GUATTARI, 1987) de seus movimentos, as cartografias experienciais constituem a base da experiência para as crianças e outros aprendizes. A esquizofrenia das máquinas computacionais é limitada em termos de habilidade de aprendizado, mesmo nos sistemas conexionistas, em virtude da necessidade de uma programação prévia. Isto constitui a lógica 
“maquínica" dos computadores. Máquinas, no sentido literal, podem ser projetadas. Os seres - humanos e não-humanos -desenvolvem-se através da experiência.

A descrição literal de Sengers das máquinas esquizofrênicas e dos aparatos tradicionais da inteligência artificial contrasta, portanto, com o uso figurativo que fazem Deleuze e Guattari da "esquizofrenia" e do "maquínico", precisamente no momento em que o sujeito 'traça o mapa' de sua trajetória no tempo, um mapa que só faz sentido em si mesmo e que só pode ser compreendido, ou no mínimo sentido, como continuidade. A tentativa de Deleuze e Guattari de "pintar” o esquizofrênico como um sujeito político desterritorializado deve ser apreendida nos termos da crítica política e dos objetivos propostos pelos dois autores nos dois volumes de Capitalismo e Esquizofrenia. Sua qualidade literal, em outras palavras, deve ser avaliada tanto em termos históricos quanto em termos políticos. A análise de Sengers sobre a esquizofrenia e sua semelhança com as máquinas vai no sentido inverso ao de Deleuze e Guattari. Consequentemente, e este é um aspecto de particular importância nos termos deste artigo, ela recusa o cyborg e outras construções pós-humanas, quer tenham ou não ligação com a perspectiva de Deleuze e Guattari da esquizofrenia e das máquinas. Sengers analisa não apenas o isolamento político dos esquizofrênicos, mas também seu isolamento psicológico, em termos da sua fragmentação cognitiva ser sintomática em suas atividades lingüísticas. A comparação desta fragmentação com aquela das máquinas contrasta, particularmente, com a concepção guattariana do "maquínico" como primordialmente um funcionalismo intercorporal e um projeto global ou hábito social. Sua ênfase, enquanto pesquisadora do campo da inteligência artificial, recai precisamente na falha das máquinas em serem socialmente funcionais, tal como acontece com os esquizofrênicos. Os contrastes entre essas duas abordagens são importantes porque revelam diferentes entendimentos da psicologia individual e social em relação à tecnologia, entendimentos que vão se refletir nas teorizações e nos próprios projetos de interface homem-computador, sistemas de inteligência artificial e modelagem cognitiva. A dimensão política das concepções de Deleuze e Guattari da esquizofrenia e das máquinas precisa ser levada em conta antes de qualquer tentativa de extensão desses termos para o campo da ciência cognitiva. 


\section{Agenciamentos Humano-Maquínicos}

Se na obra de Deleuze e Guattari o termo "maquínico", no que diz respeito aos agenciamentos humanos/orgânicos não se refere de forma direta à tecnologia, a quê se refere e de que maneira isto tem a ver com as possibilidades da IHC, em termos de uma leitura deleuziana-guattariana? A resposta a esta questão é que o termo "maquínico", na obra dos dois autores, se refere às relações nascidas dos afetos entre os corpos a partir de suas aberturas e fechamentos uns para com os outros - em outras palavras, o "maquínico" nasce da disponibilidade para os devires. Essas relações constituem lugares de sustentação do desejo. Os agenciamentos são possíveis por causa dos afetos, mas os afetos só podem ser afetivos só podem atualizar as virtualidades pessoais e contextuais e criar blocos de devir entre as entidades - se as oportunidades para isto são sustentadas pelos organismos envolvidos (as possibilidades para tanto são, ao mesmo tempo, obstruídas e facilitadas pela experiência, tanto quanto pelas regras e papeis sociais, hábitos, teorias e projetos). Sínteses conjuntivas ou disjuntivas acompanham as aberturas e fechamentos das entidades umas com relação às outras. A natureza dos agenciamentos varia de acordo com as interfaces específicas homemmáquina, e as tradições e interfaces entre teoria e projeto. (Ao analisar esses agenciamentos, a primazia concedida às interfaces homem-computador é tão somente uma questão de prioridade prática). Os humanos são seres orgânicos, e os "computadores" são mais do que um tipo de máquina, são também um tipo de máquina de calcular. A conjunção entre computadores e seres humanos tem a ver com o fato de os primeiros serem projetados pelos últimos, e do treinamento dos últimos em termos dos primeiros. As interações homemcomputador surgem dos projetos técnicos e sociais que exploram as disponibilidades recíprocas entre os dois termos.

De um modo geral, o problema da interface entre máquinas tecnológicas e seres humanos tem a ver com a natureza dos afetos e da matéria de que são compostas estas entidades, problema que costuma ser geralmente entendido como sendo da ordem da diferença entre materiais "semióticos" e "a-semióticos" (Guattari), bem como da abertura ou fechamento dos corpos e órgãos e suas possibilidades de devires recíprocos através de afetos mutuamente convergentes, caracterizados por intensidades e fluxos. Em termos deleuzianos, enquanto as máquinas tecnológicas são mais ou menos compostas de poderes possíveis de se tornarem reais, os seres vivos são feitos de poderes potenciais tornados atuais. Esta diferença leva aos limites e possibilidades ontológicas dos devires entre seres humanos e máquinas

InCID: R. Ci. Inf. e Doc., Ribeirão Preto, v. 1, n. 2, p. 03-20, jul./dez. 2010. 
tecnológicas. Enquanto as tecnologias possuem apenas alguns poderes possíveis, os homens têm tanto poderes possíveis quanto potenciais. No que diz respeito aos últimos, os homens e outros seres vivos complexos possuem poderes que hipoteticamente podem ser assumidos pela observação, mas que atuam como potenciais recursos de expressão (HARRÉ, 1998). Em contrapartida, os poderes das máquinas são quase que inteiramente projetados e construídos, e constituem uma possibilidade empírica e lógica dada a priori.

Apesar de a engenharia robótica ter cada vez mais condições de projetar máquinas capazes de manejar informações sócio-culturais e ambientais, o "pensamento" dessas máquinas permanece no plano do "possível”, mas não do "potencial”. Se a tradição metafísica que opera na ciência parece por vezes (pelo menos no nível popular) enfatizar que os organismos são seres projetados (ou seja, possuem uma causalidade pré-determinada), a ciência não é teologia e, neste sentido, a obra de Deleuze e Guattari coloca em destaque a natureza histórica e evolutiva da ação da experiência. Como parece indicar a ênfase colocada pelos dois autores sobre os objetos parciais e a temporalidade radical, a vida é uma questão de recursos para experimentação que são condições do desenvolvimento, ao passo que as bases metafísicas da modernidade tecnológica parecem ainda sugerir determinações apriorísticas e teleológicas da vida. Para Deleuze, a vida humana se estende não apenas através da extensão das possibilidades, mas fundamentalmente através do acúmulo de potencialidades individuais e suas atualizações nos acontecimentos. Para Deleuze, não existe uma origem inata das expressões mas, ao contrário, os recursos provenientes da experiência propiciam expressões potenciais e estas, por sua vez, dão forma a novas expressões. Com efeito, a natureza empiricamente hipotética e "potencial" dos seres é descrita por Deleuze e Guattari como expressão de singularidades. A noção de singularidade, desenvolvida a partir da teoria do caos e da complexidade, depende das forças de "atração pelo desconhecido" da experiência para poder expressar e dar sentido às forças constituídas nos acontecimentos anteriores. Nos organismos, esses acontecimentos referem-se às experiências que contribuem para as potenciais expressões de cada organismo. As potencialidades do self são empiricamente hipotéticas porque não podem ser verificadas como já existentes ou já possuidoras de poderes significativos, a não ser nos momentos de sua performance ou "expressão".

J. Macgregor Wise (2005) observa que a concepção de Deleuze e Guattari sobre os agenciamentos homem-tecnologia distingue-se de duas outras abordagens mais costumeiras das relações homem-máquina, a saber, aquela dos "efeitos tecnológicos" sobre os seres humanos e a da implicação contextual. Para finalizar esta seção, vamos examinar brevemente InCID: R. Ci. Inf. e Doc., Ribeirão Preto, v. 1, n. 2, p. 03-20, jul./dez. 2010. 
a argumentação de Wise para ver melhor como os agenciamentos homem-tecnologia têm sido, e podem ser, entendidos.

A primeira abordagem assinalada por Wise (2005) postula que as tecnologias são essencialmente distintas dos seres humanos. Esta visão surge com freqüência nos discursos que preconizam os "efeitos" das tecnologias sobre os seres humanos. Ela se distingue da argumentação de Deleuze e Guattari a respeito dos afetos e das forças de expressão a partir do momento em que assume que "tecnologia" é uma categoria distinta. Enquanto argumentamos que as tecnologias, assim como todas as entidades expressivas, podem ser descritas de acordo com diferentes tipos de recursos e forças, também vimos que os afetos são compartilhados entre os corpos, constituindo desta maneira um plano de imanência, um horizonte para novas expressões desses corpos. As descrições centradas nos "efeitos tecnológicos sobre os humanos" sugerem que as tecnologias surgem por fora da criação e da expressão humana. Ao invés de supor tipos ontológicos distintos em virtude de classes diferentes, Deleuze e Guattari identificam distinções e forças ontológicas em função das pausas e etapas de seus devires, marcados por diferentes aberturas e fechamentos, forças e recursos. No pensamento dos dois filósofos, categorias ontológicas são produtos das relações e evoluções históricas.

O segundo modelo apontado por Wise é o da implicação contextual. Como destaca Wise (2005, p. 82), a implicação contextual também inclui a possibilidade de os seres vivos serem "desimplicados" de seus "contextos". Esta teorização tem por base uma idéia de formaconteúdo de "contexto". Entendida e aplicada de maneira estrita, tal visão não pensa o conteúdo em termos de expressões que surgem a partir dos recursos, porque imagina este conteúdo como algo que se transfere a partir de "formas" ou "contextos". Consequentemente, a tecnologia, de acordo com esta perspectiva, é vista como algo distinto dos contextos particulares nos quais ela está implicada.

Já o terceiro modelo das relações humano-tecnológicas estudadas por Wise (2005) apóia-se nas "articulações" - que aqui discutimos em termos de expressão e afetos. Aqui as forças expressivas habitam o mundo como "máquinas abstratas" das quais as entidades participam em função de linhagens histórico-evolutivas específicas e relações sociais (cf. a este respeito, Guattari, 1995). As linhagens históricas daquilo que chamamos "tecnologia" não são nem diferentes de uma ontologia humana e tampouco são articuláveis com tal ontologia. As relações cyborg são acoplamentos a partir de relacionamentos afetivos de longa ou curta duração. Um "devir-tecnologia” torna o agente humano mais tecnológico em termos 
de suas forças e poderes; um "devir-humano" torna as tecnologias mais humanas em termos de seus poderes. Se focalizarmos as máquinas que devêm humanas, precisamos também focalizar o aspecto dos humanos devindo máquinas quando passarmos a discutir a ação e a cognição em termos de cibernética e IHC (bem como nos registros da ciência cognitiva e da IA). Além disto, se preferirmos enfocar os aparatos tecnológicos implicados na "máquina" do corpo humano, deveremos atentar para as limitações deste tipo de projeto e para a questão da evolução das máquinas autopoiéticas que se reproduzem de acordo com os recursos corporais. Enquanto o corpo evolui no sentido de melhor incorporar ou até mesmo modificar a sua função maquínica, o potencial evolutivo das máquinas tem sido, até agora, bastante limitado por sua constituição como entidades projetadas, e não como agenciamentos que se constituem a partir da experiência.

Em suma, o que se pode concluir a partir da perspectiva deleuziana-guattariana das "máquinas inteligentes" é que seu discurso é ao mesmo tempo menos e mais do que a forma com que geralmente é apreendido. É menos do que um discurso apologético do pós-humano, do cyborg, que pressupõe que as máquinas tecnológicas e as máquinas humanas podem facilmente se fundir, se hibridar. Deleuze e Guattari concebem as máquinas como relações funcionais tornadas possíveis pelos afetos e expressões, bem como por linhagens históricas e sociais que delimitam as forças de expressão. Esses dois horizontes são necessários para dar conta das interações homem-computador. Não se trata, portanto, de um discurso tecnologicamente determinado, mas, ao contrário, de um discurso das evoluções históricas dos afetos.

O entendimento de Deleuze e Guattari das relações humano-tecnológicas não se baseia em uma ontologia dos seres descolada de suas relações históricas. Tanto as "sínteses conjuntivas" quanto as "sínteses disjuntivas" entre tecnologia e seres humanos têm a ver com suas histórias comuns e distintas, marcadas por afetos comuns e também por diferenças ontologicamente determinadas. É preciso ler em todos os textos de Deleuze e Guattari as entidades como expressões evolutivas das relações históricas e sociais. 


\section{Considerações finais}

Meu objetivo neste artigo foi estabelecer um diálogo entre as teorizações de Deleuze e Guattari a respeito da psicologia e da tecnologia com aquelas das ciências cognitivas, inteligência artificial e interação humano-computador. Embora uma concepção bem geral do afeto pudesse ser um eixo de articulação entre esses dois blocos discursivos, é preciso considerar que existem diferenças importantes. Em primeiro lugar, o vocabulário comum aos dois discursos precisa ser contextualizado para não confundir ou generalizar posições e tradições particulares e bem específicas. Precisamos ser cuidadosos para evitar uma pretensiosa generalização interdisciplinar. Em segundo lugar, é preciso estar atentos aos diferentes compromissos epistemológicos das duas linhas discursivas: enquanto Deleuze contrapõe a uma tradição metafísica do sujeito uma linha de pensamento derivada de uma distinta tradição filosófica - aquela do expressionismo - a ciência cognitiva e a IA vêm reproduzindo as premissas ontológicas e epistemológicas da tradição metafísica do pensamento ocidental (EKBIA, 2008). Finalmente, enquanto a noção de afeto de Deleuze e Guattari compreende as expressões cognitivas, emocionais e corporais como diferentes atributos de uma entidade, os modernos discursos científicos tendem a subdividir essas expressões em termos de diferentes características ontológicas e epistemológicas, e até mesmo fisiológicas (por exemplo, a primazia dos neurônios no cérebro) e valores sociais (como o valor do trabalho, etc.) a elas atribuídas.

Em suma, se por um lado a discussão desenvolvida por Deleuze e Guattari (1994) sobre o cérebro, e o comentário de Watson a este respeito, reforçam nossa crença na possibilidade de um diálogo comum em direção a uma nova psicologia, por outro, as ambigüidades e diferenças entre as duas abordagens requerem que sejamos cautelosos no sentido de uma extensão exagerada desta hipótese, que demanda mais aprofundamento e investigação crítica.

InCID: R. Ci. Inf. e Doc., Ribeirão Preto, v. 1, n. 2, p. 03-20, jul./dez. 2010. 


\section{Referências}

DELEUZE, G. Postscriptum on control societies. IN: Negotiations. New York:

Columbia University Press, 1990. p. 177-182.

Bergsonism. New York: Zone Books, 1991.

Difference and repetition. New York: Columbia University Press, 1994.

What children say. IN: Essays critical and clinical. Minneapolis:

University of Minnesota Press, 1997. p. 61-67. 2004.

Francis Bacon: the logic of sensation. Minneapolis: University of Minnesota Press,

DELEUZE, G.; GUATTARI, F. Anti-Oedipus: capitalism and schizophrenia. Minneapolis: University of Minnesota Press, 1983.

A thousand plateaus: capitalism and schizophrenia. Minneapolis: University of Minnesota Press, 1987.

1994.

What is philosophy? European perspectives. New York: Columbia University Press,

EKBIA, H. R. Artificial dreams: the quest for non-biological intelligence. Cambridge:

Cambridge University Press, 2008.

GUATTARI, F. On machines. Journal of Philosophy and the Visual Arts, n. 6, p. 8-12, 1995.

HARRÉ, R. The singular self: an introduction to the psychology of personhood. London: Sage, 1998.

ORR, J. Panic diaries: a genealogy of panic disorder. Durham: Duke University Press, 2006.

SENGERS, P. Schizophrenia and narrative in artificial agents. Leonardo, v. 35, n. 4, p. 427431, Aug. 2002.

WATSON, S. The neurobiology of Sorcery: Deleuze and Guattari's Brain. Body and Society, v. 4, n. 4, p. 23-45, 1998.

WIENER, N. The human use of human beings: cybernetics and society. New York: Da Capo, 1988.

WISE, J.M. Assemblage. IN: STIVALE, C. J. Gilles Deleuze: key concepts. Montreal: McGill-Queen's University Press, 2005.

Traduzido por: Leonora Corsini e Solange Puntel Mostafa

Revisado por: Denise Viuniski da Nova Cruz

Artigo submetido em 20 nov. 2010

Artigo aceito em 15 dez. 2010

InCID: R. Ci. Inf. e Doc., Ribeirão Preto, v. 1, n. 2, p. 03-20, jul./dez. 2010. 